\title{
Value Added by Interoperable Information Systems in Spread Production Networks
}

\author{
Dirk Oedekoven, Volker Stich, and Bojan Stahl \\ Research Institute for Operations Management at RWTH Aachen University, \\ Pontdriesch 14/16, 52062 Aachen, Germany \\ \{Volker.Stich, Dirk. Oedekoven, Bojan.Stahl\} afir.rwth-aachen.de
}

\begin{abstract}
What is the competitive advantage of interoperable information systems? Taking this research question as a guideline the paper discusses how to approach the challenge of assessing the benefits of integrated systems. The main focus is laid on the direct and indirect effects of standardization projects which aim at continuous and homogenous order processing data. The knowledge based approach starts on data level and takes care of the interdependencies between the subsequent levels of aggregation. The problem immanent complexity is caused by the variety of heterogeneous product and process describing attributes. The application of management cybernetics in order to handle this challenge constitutes the focal point of this paper.
\end{abstract}

Keywords: interoperability of information systems, standardization, management cybernetics, value added, order processing architecture.

\section{Introduction}

\subsection{Initial Situation and Conceptual Background}

The European Union (EU) is presently funding a research project (IMS2020) fostering the achievement of "Sustainable Manufacturing, Products and Services" by the year 2020. The project team consists of industrial and research competences from all over the world. Leading institutes and enterprises from Switzerland, United States, South-Korea and Japan participate from the beginning of 2009 until the end of 2010.

One of the main activities of IMS2020 is the identification of relevant research topics to set up a Roadmap describing how to achieve the desired vision of the year 2020. In fact, 20 world wide existing roadmaps and 13 ongoing research projects have been mapped, identifying a total of 754 Research Issues. The development of the Roadmaps has been supported by collaborative tools shared with all the Roadmapping Support Group, a growing community that, at the moment, counts 254 participants from 108 mainly industrial organizations. The project is embedded in the global activities of the Intelligent Manufacturing Systems (IMS) initiative. This initiative is a platform for industrial research to share experience and best practices.

The first steps, after the mapping, have been an open online survey, with 261 participants, two brainstorming workshops and 106 interviews. All these activities 
involved experts not only from Europe, but from all over the world, with special focus on the IMS regions (Japan, Korea, US). Based on these inputs, the IMS2020 team developed a vision for the 2020 manufacturing with a set of 62 Research Topics to be implemented in order to achieve it. These topics have been shared and refined with the input of the community through an online wiki (http://ims2020net.wik.is/) that has more than 2500 visits up to now. Finally the research topics have been validated and prioritized through a second online survey $(n=359)$. Additionally the interest of the different IMS regions to participate in corresponding collaborative research projects has been taken into account.

Sustainable manufacturing can be defined as "[...]the vision of a production system, in which production and consumption support the quality of individual and social life, in ways that are economically successful while respecting environmental limits. Knowledge and technology, capital, resources and needs are harnessed and governed so people can live better lives while consuming less material resources and energy" [26]. To achieve the goal of consuming less material resources and energy it is important to avoid any kind of waste. This is valid for specific production procedures as well as for all superior supply chain coordinating processes. For that reason it is not remarkable that the investigation of possible research topics led to the problems caused by inconsistent and redundant data.

In the past decades production systems became more and more spread all over the world. The increasing number of multi-site enterprises imposes a tremendous challenge to the performance especially of enterprise resource planning (ERP) systems. Furthermore cross-company processes within the order management are steadily gaining importance. Companies realize efficient communications with their network partners as competitive advantages. Efficient and real time information sharing is more and more understood as a strategic instrument affecting the value of the company [3][4][5][6]. The growth of importance of IT infrastructure has increased disproportionately high since the 80ies [1][2]. Nevertheless, enterprises struggle fighting the problem of inconsistent and redundant data. On the one hand they are not able to avoid the appearance of these challenging effects. In consequence this leads to an inadequate support of cross-sectional order processing tasks. On the other hand the benefits of required projects to harmonize and standardize data and data structures cannot be evaluated with an adequate accuracy in advance. The value added by interoperable information systems is not known. In the end projects run out of budget or are not even launched although there is a high potential for improving processes and gaining competitiveness.

Coming up in a lot of expert interviews as well as in a high number of survey returns this problem put the IMS2020 consortium to call for a sustainable management concept in one of its research topics. Especially product and process describing data with relevance for order processing should be in the centre of attention (RT1.20). Following this intention the underlying research work of this paper investigates how to estimate the competitive advantage of harmonization and standardization projects by making use of knowledge about the interdependencies among benefit dimensions. 


\subsection{Problem Definition}

Knowledge about the actual state of work is nowadays an indispensible competitive advantage acting on global markets. The competitiveness of an enterprise is not any longer defined only by its products and services but in fact by its ability to execute orders at maximum efficiency. Information is required to be accessible in real time and across all levels of production management. Nowadays a companies IT infrastructure is characterized by a high number of applied IT solutions. Taking a look at the process of order handling it becomes obvious that relevant data will not only be found in ERP Systems. Product Data Management (PDM), Product Lifecycle Management (PLM), Manufacturing Execution (MES) and even systems for production data acquisition (PDA) on shop floor level contain important knowledge for excellent order handling processes as well. The economic and logistic potential within the system interfaces is enormous, independent if it is rooted in intra company networks or among autonomous companies [7][8][9]. The challenge is originated in spread production systems.

Identical products do not automatically guarantee synchronized process- and attributes structures. Not standardized processes lead to inadequate ERP system support, even if the objects and objectives are consistent. The results are inefficient information flow and poor transparency. The coordination between the different facilities is time-consuming and costly because integration and standardization potentials are not utilized. In addition the potential to integrate modern concepts of cooperation into operational and cross-site planning habits remains limited. Last but not least, the extent of the corresponding influences on the company's key figures (e.g. ROCE) cannot be determined currently. The interoperability of a company is affected and remains far below its natural potential.

For that reason harmonization activities are needed, that create an integrated, accurate and consistent data basis for all company-relevant master data [10]. An

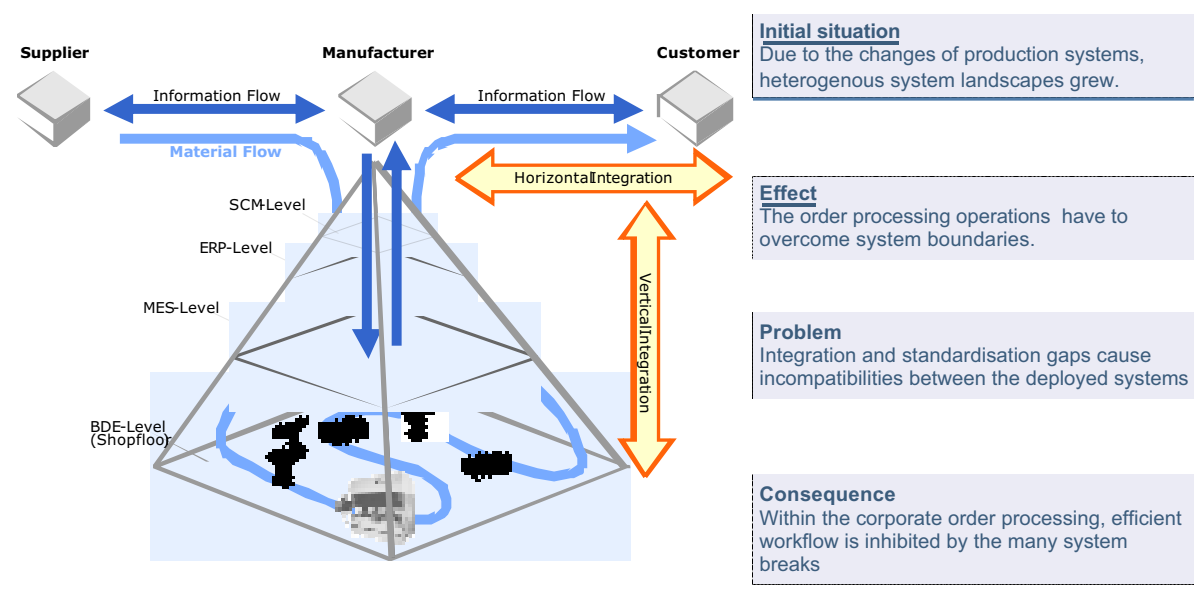

Fig. 1. Initial Situation 
investment to a harmonization plan as an IT project remains undone, if only one of the involved entities appreciates the not negliable investment as too expensive, project risks as too high and the profitability ex ante not to be identified [11]. In times of intense global competition it is of particular importance, to ensure the plausibility of costly large-scale projects in terms of their real potential benefits. Otherwise companies are risking their existential business actions through wasting liquid funds. The value added must become assessable.

A segmentation of the system discontinuities' causes helps to structure the problem: On the one hand supply relations between the entities of a production network exist but the use of different ERP systems determines physical incompatibility of the interfaces. This case can be described as the integration gap. On the other hand compatible ERP systems are used, but semantic differences in the order processing data lead to incompatibilities. This can be summarized as the standardization gap [APMS proceedings]. The closure of integration- and standardization gaps through corresponding harmonization projects is the precondition for interoperability. Accordingly this segmentation will be regarded as a guideline for the ongoing research work and help to quantify the value added by interoperable information systems in spread production systems.

\subsection{Objective of Research Work}

The objective of this research work is to develop a method for the identification and estimation of the benefit potential of harmonized order processing attributes and data. The focus is on companies which act within the frame of spread production systems. The method should be useable to support decision processes regarding investments into corresponding harmonization projects within a company, a group or a network. It should provide an assistance to enable and raise the rationality of the decision and modern techniques to analyse cost-benefit potentials.

Furthermore it is explicitly important to consider the induced dynamics, variety and complexity. This will be guaranteed by locating the respective processes in a reference model that fits these requirements.

To provide useful results the development of the method has to include an investigation of all relevant interdependencies regarding the single benefit dimensions. A preceding analysis of the underlying complex structure identifying each relevant benefit dimension is indispensable. As different effects can occur whether in reinforcing or in inhibiting affection the necessary exploration of the corresponding relations can be processed from there on. This should lead to a deduction of the correlations between the single dimensions of benefit and the underlying heterogeneous data. Finally the qualitative benefits of potential should become assessable on a monetary level despite some uncertainties making use of such functional chains.

\subsection{Scope of Research Work}

Existing assessment approaches usually focus on the implementation of specific systems such as SCM or ERP applications only. Indeed, harmonization projects should not only be qualified by verifying their contribution to a single systems 
performance. Furthermore it is essential to become aware of the total impact on all strategic goals, which usually affect vertical and horizontal integration and standardization needs.

To narrow the scope of investigation contract manufacturers of products with variants are the initial point of work. Furthermore it is necessary to stick to processes that are suited as references of real actions. An analysis of reference processes ensures a complete enumeration of all interfaces that may suffer from heterogeneous data and attributes in and between enterprises. Accordingly for each interface a number of potentials can be identified. In order to structure potentials and relations the set-up of a benefit model comes into place. By developing a coherent target system connecting subordinate objectives of data harmonization with superior objectives such as cycle time reduction, the interdependencies can be evaluated. Starting from a detailed reference model, making use of knowledge about functional chains and ending up in an integrative assessment based on an overall target system is essential.

Regarding information flows the Aachener PPC Model offers the most detailed and feasible reference model of order processing activities [13]. SCHMIDT amends this model by a description of the coordination points in 2008 [27][28]. But although the additional modelling of control loops concerns science as well, an explicit analysis and description of product and process describing data is still missing. Taking this spadework to another level several authors investigated the functional chains of benefit effects while having different target systems in mind [14][17][21]. A continuative connection of product and process data with any of the target systems is not performed. A universally valid model of respective functional chains keeps missing. Only a few authors try to elaborate the impact of IT integration but they keep focussed one specific system. They do not have the fundamental process of order processing in mind [21].

So far, there is no accordant technique which addresses the deduction of potentials that occur from a harmonization of product and process describing data in terms of order processing requirements.

\section{Research Design}

The course of action described below is geared to the approach to research according to ULRICH [15]. The research focuses on the effects of data harmonization regarding the monetary success of the companies. The description and explanation of the impact of data harmonization projects is the aim of the research work. The steps of the research process include terminological-descriptive, empirical-inductive and analytical-deductive components [16].

First of all the problem is embedded within management cybernetics. The order processing procedure is characterized by an interaction of diverse participants as well as by a high number of systemic interfaces. This results in a complex interplay of the entire observed systems which is difficult to be dealt with for a scientific analysis. In literature various models try structuring order processing activities according to a certain classification scheme in order of an integrative description of information interfaces. However, due to their focus and level of detail they do not afford a sufficient categorization of the diverse starting points for harmonization projects. 
In this research work, management cybernetics is used as a starting point and initial approach for identifying potential benefits. The Viable System Model (VSM) has to be adapted in order to fulfil the research requirements which emerge from the consideration of dynamic effects. Hence, it serves as an essential basis for the description model.

The second step involves the identification and localization of harmonization objects. In this case, harmonization objects are specific spots in the process which require certain coordination. Those spots are indicated by shifts from one medium into another, involvement of different types of information and the constraint to be crucial in decision-making or producing new information. Hence, the term harmonization object can be defined as certain step in the order processing, where incongruent data and/or the usage of different, not-connected IT systems finally lead to an increase of decision-making complexity. The harmonization object is therefore a part of the entire process, where those states can be identified. Harmonization demand causes negative consequences in the end to the monetary ratios of an enterprise which e.g. is done by longer work, information comparison tasks and reliable tasks. Therefore, the localization of harmonization objects within the entire order processing chain serves as a first step. In order to gain comprehensive results all information processed through all systems and activities in the sub-process are gathered and analysed.

The harmonization objects arise from diverse typologies of causation, whereas in fact two different types can be differentiated. First order harmonization demand is existent if the same information is described by two syntactical different data sets. Second order harmonization demand is existent if a data set is changed and saved in another IT-system, so that the identical information has two different characteristics. Those harmonization demands lead to harmonization objects. As stated above, harmonization objects are steps in the order processing where harmonization demands of first or second order or a combination of both can be identified.

The functional analysis of the harmonization objects' influence on specific target elements prepares the ground for the final assessment. The target system, based on the spadework of FIR [22], lists all important and necessary management ratios on different hierarchical levels with certain dependencies. The identification of the decisive interdependencies between harmonization objects and elements of the target system is a crucial step. The proper assessment and estimation is the initializing path towards a monetary evaluation of the potential benefits of harmonization projects. An accurate detailing is therefore pivotal.

Finally the design of a procedure for identification and assessment of potential benefits in harmonization projects is performed. The procedure is structured by three steps. The first one leads to an evaluation of each harmonization object. Secondly, the effect to a single business ratio is determined. Finally, an instruction for accumulation is given.

In the end, the accomplishment of several activities leads to the method that has to be developed for the identification and assessment of potential benefits in harmonization projects. It includes the specification of various potential benefits and costs as well as the systematic analysis of the interdependencies referenced to an integrated target system. The following will give a brief overview how the VSM was 
applied in terms of management cybernetics to ensure a resilient reference model as an initial point of work.

\section{Management Cybernetics}

The conventional methods of the model theory do not provide fitting approaches to face the system-immanent complexity of production systems. On the contrary systems theory and management cybernetics specifically start at this point. In contrast to the general approach of engineering or business sciences, these approaches do not exclude the complexity through restrictions and simplifying assumptions, but are setting the focus on it. The discipline of management cybernetics founded by BEER delivers receipts and methods to manage the company effectively because of a system oriented approach [12].

\subsection{Viable System Model}

The Viable System Model (VSM) was developed by Stafford Beer upon a trilogy of his publications [18][19][20]. BEER created the VSM in analogy to the human nervous system in regard to homomorphism and assigned the principles of control patterns of a living and life-sustaining biological system to social systems in order to adapt the attribute of system performance. Thus, it executes various operations like adjustment to changes in the environment and self-coordination of its parts. It contains multilevel combined closed-loop systems and consists of an adequate and inevitable set of organizational functions for viable organizations and is able to maintain the organizational structure as well as to install internal stabilization, whereas from a cybernetics perspective viable means to maintain a separate existence. The VSM is a recursive system, where each VSM contains and is contained within other viable systems [19].

The VSM displays companies independent from their size or branch into a system with five subsystems with identical structures. The VSM is a cluster of operations, management and the environment and it provides design techniques regarding information, material and energy flows. Hence, the VSM defines principles for organizations that need to be fulfilled in order to maintain viability. A VSM is composed of five interacting subsystems which are described below.

System 1 incorporates the operations and primary activities where the system's purpose is fulfilled. The entire operation unit may contain several System 1. Every System 1 consists of a management and operation unit which is connected due to certain principles to the environment and other systems.

The other systems are so called meta-systems which means they are above logical order. They perform as a management unit and control system for the operation units.

System 2 performs the coordination of the operation units. Typical specifications are information systems, coordination teams or internal service units. The behavior of the autonomous operating System 1 has to be adjusted in order to prevent dysfunctionalities and oscillation.

System 3 is the operative planning and therefore responsible to ensure efficiency in the operation's performance. It is accountable for the internal control of the organization and functions as a supervisor for the System 2 activities. System $3 *$ is 
directly connected to System 3. It fulfills direct monitoring operations in System 1 via sporadic audits and supports System 3 with necessary information about the operations performance.

The main purpose of System 4 is to gather information from the environment, to separate it, and to generate potential future models of the environment and the organization. It derives and develops strategies for prospective corporate development.

System 5 is the normative management. On the one hand it is responsible for the interaction of the operation and strategic management, and on the other hand represents the corporate values, norms and rules. It builds the ethic and culture of an organization [19].

The information generated from and by management activities is distributed through the closed-loop channels between the five subsystems. Every system has a certain configuration of information type executed and processed to other systems:

- System 1: Information about the primary activities and information that is forwarded between the operating systems

- System 2: Information that is required to assure harmonization between all the operating systems

- System 3: Information that is used to enhance the operating S1 systems activities

- System 4: Information from the environment and from the organization that is significant to strategic development

- System 5: Information of a normative quality

The Viable Production System (VPS) serves as an organizational corporate model to understand and explain the flow of information in the company regarding the control of processing of orders. Particularly, the information processed by the meta-system is in focus.

\subsection{Viable Production System}

The structure of the VPS is defined by the application of the order transaction processes of manufacturing companies to the operational systems of the VSM. It is characterized by a concurrent appearance of a process-oriented view as well as an organizational control-oriented-view in one holistic enterprise model method.

According to SCHMIDT, the order processing consists of nine key processes: process offer, projecting, product design, order executing, parts procurement, parts production, parts assembly, distribution and after sales service [22]. Furthermore, the key processes can be divided from sub-processes to employee level. The nine key processes establish the nine main activities of the Systems 1 in the first recursion level in order to afford major autonomy. Taking an ideal case as a basis the order processing can be proceeded without further intervention of the control units or the meta-system. The control units are assigned with two tasks:

- $\quad$ process monitoring to handle disturbances

- organizing the operational elements according to guidelines of the metasystem 


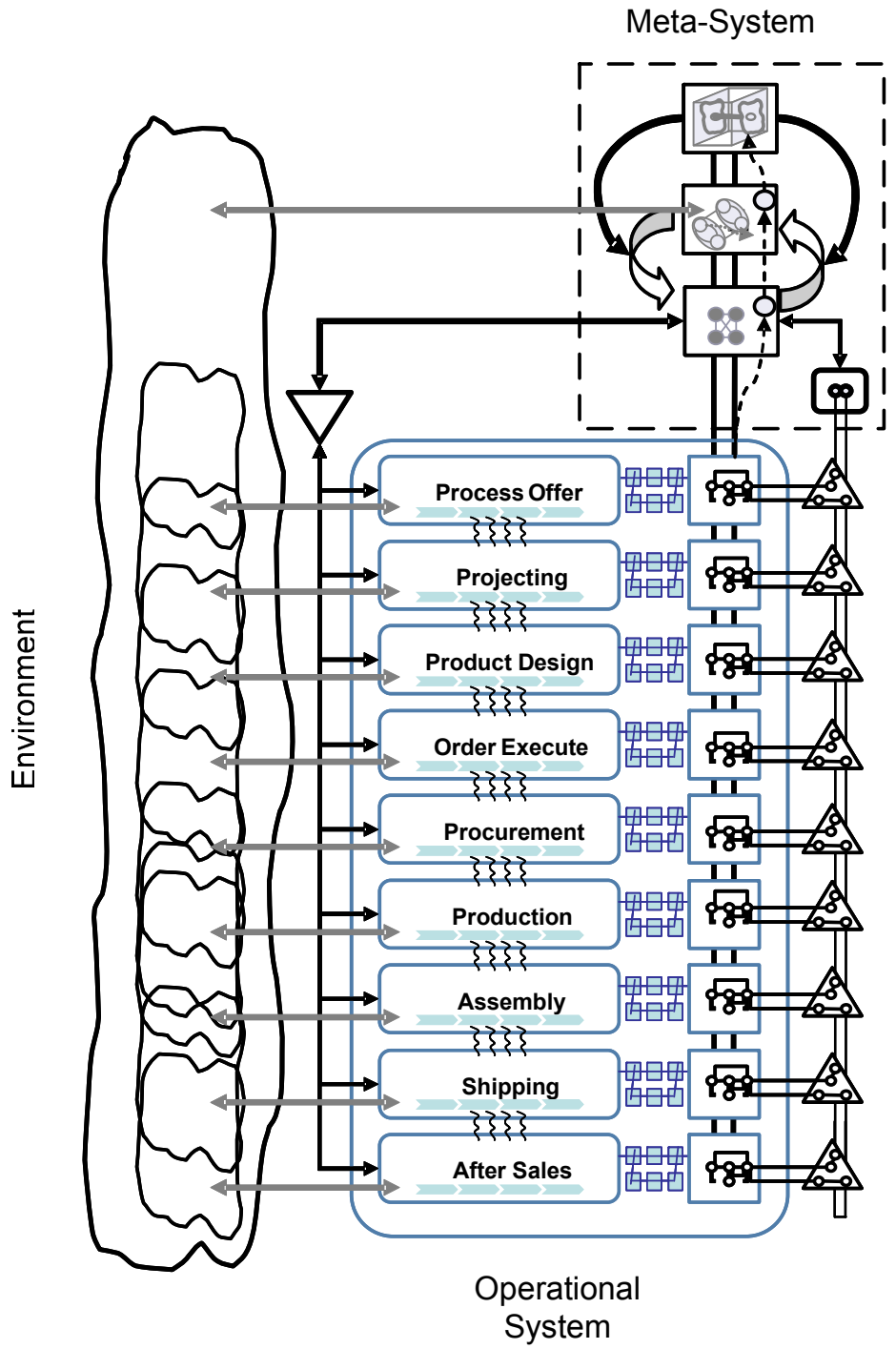

Fig. 2. Viable Production System [23] [24]

The application of the VSM broadens the limited stand alone process view by a further dimension. While the process model arranges the key processes and flow of information among one other, it is able to map the monitoring, control and disturbance functions within the VSM [23][24].

The advantage of the VPS is the stringent orientation on the order processing in conjunction with the current examination of the process and control level. Hence, the opportunity of a holistic embodiment is provided. The corporate application of the VPS is still a challenge to be dealt with. Another focus of research interest for this survey is provided by the anastomotic reticulum. Within the VSM, the anastomotic 
reticulum serves as the direct connection between the operational units. Information, energy and material can be transmitted through the respective channels of the net in order to fulfil the operational aims. An anastomotic reticulum is a model of a neuronal net in which every neuron listens and speaks to many [25]. This means that the various connections of a network are compound in such a manner that it is no longer possible to detect how the information has passed the network. Comparable to a river delta it is impractical to determine where one particle comes from and goes to. It seems unfeasible to track a single particle in the water. Information streams in management or social systems appear with the same attitude [18].

Whereas the residual channels of the VSM serve for variety engineering and control mechanisms, the anastomotic reticulum is the main connection in terms of a systems purpose. Therefore, this network is an essential research object when dealing with the order processing without considering a certain control mechanism.

The VPS concentrates on the control systems of an order process and is engaged in the information flow of the meta-system. The connections between the meta-system and operational system are on focus as well as the channels within the meta-system. This research tries to bridge the gap within the VPS and centres its work on the information flows between the operational systems which is neither covered in the VPS and VSM at present.

\section{Results and Conclusion}

The challenge for enterprises of being efficient and effective in using their IT infrastructure is gaining more and more importance. Yet a promising approach to evaluate potential benefits in advance is missing. In the field of profitability analysis of order processing in spread production structures the difficulty lies more within the estimation of benefits rather than in the estimation of the efforts. The monetary analysis of benefit potentials is so far limited to quantitative dimensions, while the qualitative aspects stay neglected or analyzed on a general level only.

As the mediate potentials of benefit at harmonization projects have a high total ratio, the validation of the effects on a monetary key figure for those systems is highly relevant. The interdependencies between the dimensions of benefit were so far only analyzed isolated and without regarding of cross-sites effects. Functional chains analyzed so far do not give a detailed description of the influencing mechanisms, apart from quantifying positive or negative influences. By that it can be stated that a systematic, scientifically founded derivation of the benefit potentials of harmonized data objects has not been performed yet. A corresponding option to assess potential benefits efficiently and exemplify their interdependencies is missing as well. Complexity could be identified as the main causes for this failure.

The VPS in general and the anastomotic reticulum in particular frame a suitable approach to meet the evolving requirements. The anastomotic reticulum can be specified due to the transmitted types and the mode of connection. Information, energy and material are the distinguishable types which are interchanged by the operational units. The mode of connection is determined by the specified Systems 1, where human or technological channels can be differentiated. Especially the 
technological channels can be developed as machines, conveyors, programmes, applications, emails, information systems, power lines, faxes and many more.

BEER has stated that a specific survey of the anastomotic reticulum is not practical due to its nature. Taking the examples from above into account, it is obvious that a post-correlation how all the different types proceed and the identification of the sender or receiver is clearly too complicated. For that reason containment is necessary in terms of the research topics' focus. Due to the absence of material and energy in business processes only information needs to be taken into account as a transmitted type. The containment of the mode of action turns out to be more precise than a separation into human or technological channel. Because the VPS and this research focuses on the harmonization potentials regarding IT-supported order processing activities, all information systems which have a relevant impact on the business process have to be distinguished. These distinguishable information systems build the so called primary systems (e.g. ERP-Systems, etc.). All other modes of connections which do not count as information systems by definition are gathered as the so called secondary systems (e.g. email applications, etc.). Hence, the object of research requires the distinction between the several information systems known as primary systems and secondary systems. Latter have not to be splitted further.

It is not necessary to determine how information finds its way from a sender to a receiver. Due to the conjunction of the business process analysis concept and recent applied information technology systems, the potential sender and receiver can be identified independently from time constraints. The nature of the anastomotic reticulum can be examined due to the selective choice of relevant observation objects. The relation between certain information and level of information can be studied by a comparison of the different information systems and secondary channels. Consequently, the reticulum has to be understood as the localization of enterprises harmonization potential.

This finding is the missing link which inhibited a holistic assessment of the harmonization potential so far. On the one hand the identification, categorization and assessment of potential benefits and costs become possible. On the other hand the consideration of the functional interdependencies between the various benefit dimensions ensures valid results.

\section{References}

1. Kernler, H.: PPS der 3. Generation: Grundlagen, Methoden, Anregungen. Hüthig, Heidelberg (1995)

2. Krcmar, H.: Informationsmanagement. Springer, Berlin (1997)

3. Schuh, G., Friedli, T., Kurr, M.A.: Kooperationsmanagement. Hanser, München (2005)

4. Arnold, B.: Strategische Lieferantenintegration. Dissertation Technische Universität Berlin. Deutscher Universitäts-Verlag, Wiesbaden (2004)

5. Lee, H.L.: Creating value through Supply Chain Integration. Supply Chain Management Review 4(4), 30-36 (2000)

6. Ihde, G.: Lieferantenintegration. In: Kern, W., Schröder, H.-H., Weber, J. (eds.) Handwörterbuch der Produktionswirtschaft: Enzyklopädie der Betriebswirtschaftslehre VIII, pp. 1086-1095. Schäffer-Poeschel Verlag, Stuttgart (1996) 
7. Schuh, G.: Referenzstrategien in einer vernetzten Welt. In: Milberg, J., Schuh, G. (eds.) Erfolg in Netzwerken, pp. 17-34. Springer, Berlin (2002)

8. Schönsleben, P., Luczak, H., Nienhaus, J., Weidemann, M., Schnetzler, M., Roesgen, R.: Supply Chain Management: Monitoring-Lösungen auf dem Vormarsch. IT-Management 5, 10-17 (2003)

9. Busch, A., Lange, H., Langemann, T.: Marktstudie zum Collaborative Supply Chain Management. Heinz Nixdorf Institut, Paderborn (2002)

10. Möbus, D., Richter, G.: Stammdatenstrategie: Nur ein IT Thema?

http://www.cio.de/_misc/article/printoverview/

index. cfm?pid=181\&pk=851640\&op=1st

11. Rautenstrauch, T.: SCM-Integration in heterarchischen Unternehmensnetzwerken. In: Busch, A., Dangelmaier, W. (eds.) Integriertes Supply Chain Management, pp. 341-361. Gabler, Wiesbaden (2002)

12. Beer, S.: Kybernetik und Management. Fischer, Frankfurt (1959)

13. Schuh, G.: Produktionsplanung und -steuerung. Springer, Heidelberg (2006)

14. Retter, G.: Ein prozessorientiertes Wirtschaftlichkeitsanalyseverfahren zur Bewertung von Informationssystemen anhand strategischer Wirkungen. Dissertation RWTH Aachen (1996)

15. Ulrich, H.: Die Betriebswirtschaftslehre als anwendungsorientierte Sozialwissenschaft. In: Geist, N., Köhler, R. (eds.) Die Führung des Betriebes, Poeschel, Stuttgart, pp. S1-S15 (1981)

16. Hill, W., Fehlbaum, R., Ulrich, P.: Organisationslehre 1: Ziele, Instrumente und Bedingungen der Organisation sozialer Systeme, Haupt, Bern (1994)

17. Spiess, M.: Eine Methode zur Nutzenerfassung von Teleservice. Dissertation RWTH Aachen (2003)

18. Beer, S.: Brain of Firm. Wiley, Chichester (1981)

19. Beer, S.: Heart of Enterprise. Wiley, Chichester (1979)

20. Beer, S.: Diagnosing the system for organizations. Wiley, Chichester (1995)

21. Lin $\beta$, H.: Integrationsabhängige Nutzeffekte der Informationsverarbeitung: Vorgehensmodell und empirische Ergebnisse. Deutscher Universitäts-Verlag, Wiesbaden (1995)

22. Schmidt, C.: Konfiguration überbetrieblicher Koordinationsprozesse in der Auftragsabwicklung des Maschinen- und Anlagenbaus, Dissertation RWTH Aachen (2008)

23. Brosze, T., Bauhoff, F., Stich, V.: High Resolution Supply Chain Management Resolution of the polylemma of production by information transparency and organizational integration. In: Proceedings of the International IFIP TC 5, WG 5.7 Conference on Advances in Production Management Systems (APMS 2009). University of Bordeaux 1, Bordeaux (2009)

24. Brosze, T.: High Resolution Supply Chain Management. Unternehmen der Zukunft 10(1), $15-17$

25. McCulloch, W.S.: Embodiments of Mind. MIT Press, Boston (1988)

26. Geyer, A.: The challenge of sustainable manufacturing - four scenarios 2015-2020. In: International Summer Academy on Technology Studies - Corporate Sustainability (2007)

27. Schuh, G.: Effiziente Auftragsabwicklung mit myOpenFactory. Hanser, München (2008)

28. Schmidt, C., Meyer, M.: Plug and do business - ERP of the next generation for efficient order processing in dynamic business networks. International Journal of Internet and Enterprise Management (IJIEM) 2(2), 152-162 